ORIGINAL ARTICLE

\title{
Motor vehicle trauma: analysis of injury profiles by road-user category
}

\author{
H Markogiannakis, E Sanidas, E Messaris, D Koutentakis, K Alpantaki, A Kafetzakis, D Tsiftsis
}

Emerg Med J 2006;23:27-31. doi: 10.1136/emj.2004.022392

See end of article for authors' affiliations

Correspondence to: Dr H Markogiannakis, Kerasoudos 54, Zografou, 15771 Athens, Greece; markogiannakis@easy. com

Accepted for publication 8 April 2005

\begin{abstract}
Background: Vehicle accidents in Greece are among the leading causes of death and the primary one in young people. The mechanism of injury influences the patterns of injury in victims of vehicle accidents. Objective: Identification and analysis of injury profiles of motor-vehicle trauma patients in a Greek level I trauma centre, by road-user category.

Patients and methods: The trauma registry data of Herakleion University Hospital of adult trauma patients admitted to the hospital after a vehicle accident between 1997 and 2000 were retrospectively examined. Patients were grouped based on the mechanism of injury into three road-user categories: car occupants, motorcyclists, and pedestrians.

Results: Of 730 consecutive patients, 444 were motorcyclists (60.8\%), 209 were car occupants (28.7\%), and 77 were pedestrians (10.5\%). Young men constituted the majority of injured motorcyclists whereas older patients $(p=0.0001)$ and women $(p=0.0001)$ represented a substantial proportion of the injured pedestrians. With regard to the spectrum of injuries in the groups, craniocerebral injuries were significantly more frequent in motorcyclists and pedestrians $(p=0.0001)$; abdominal $(p=0.009)$ and spinal cord trauma $(p=0.007)$ in car occupants; and pelvic injuries $(p=0.0001)$ in pedestrians. Although the car occupants had the highest Injury Severity Score (ISS) $(p=0.04)$, the pedestrians had the poorest outcome with substantially higher mortality $(p=0.007)$ than the other two groups.

Conclusions: The results reveal a clear association between different road-user categories and age and sex incidence patterns, as well as outcomes and injury profiles. Recognition of these features would be useful in designing effective prevention strategies and in comprehensive prehospital and inhospital treatment of motor-vehicle trauma patients.
\end{abstract}

V hicle accidents continue to be a major public health problem with increasing contribution to mortality, morbidity, and disability. Vehicle trauma is the leading cause of death in young people and one of the commonest causes of death overall. ${ }^{1}$ The number of people dying from road traffic accidents exceeded 30 million in the last century, and nowadays nearly 1 million are killed and more than 10 million injured annually worldwide. ${ }^{2}$

In Greece, trauma is the leading cause of death among people under 40 years of age, and the fifth commonest cause overall. ${ }^{3}$ Road traffic accidents account for over a third of all deaths in the 15-39 year age group. ${ }^{5}$ Every year over 2000 people are killed and 32000 injured (table 1). Greece has one of the highest rates of death after a vehicle accident per million population in the European Union, ${ }^{6}$ and, in the past three decades, together with Spain and Portugal, ranked among those countries in the European Union where consequences of motor vehicle crashes relative to the number of registered vehicles have been the highest. ${ }^{78}$

The mechanism of injury influences the patterns of injury seen after vehicle trauma. Previous reports have attempted to delineate the epidemiological characteristics, injury profiles, and contributing risk factors among the various categories of road-users. ${ }^{9-14}$ Knowledge of these features is a key element in identification and evaluation of preventive actions, and it has important clinical implications concerning the care of these patients.

The present study examined the population of adult motorvehicle trauma patients admitted to a university level I trauma centre in Greece. Our objective was to investigate and analyse the demographic features and injury patterns and outcomes among these patients to $(a)$ assess the magnitude of the problem in Greece, $(b)$ identify potential, associated risk factors, and (c) in particular, identify the variations between patients in different road-user categories.

\section{PATIENTS AND METHODS}

This study is a retrospective analysis of data collected prospectively through the trauma registry of the level I University Hospital of Herakleion, Crete, Greece. The

Table 1 Road traffic accidents and outcomes in Greece (1985-99)

\begin{tabular}{lllll}
\hline & Total no. of & No. of fatal & \multicolumn{2}{l}{ No. of injured } \\
Year & accidents & accidents (\%) & people & No. of deaths \\
\hline 1985 & 21461 & $1608(7.5)$ & 32884 & 1834 \\
1986 & 22239 & $1536(6.9)$ & 30775 & 1720 \\
1987 & 23245 & $1537(6.6)$ & 31189 & 1750 \\
1988 & 23853 & $1568(6.6)$ & 33414 & 1768 \\
1989 & 23692 & $1730(7.3)$ & 33355 & 2012 \\
1990 & 22644 & $1760(7.8)$ & 31145 & 1981 \\
1991 & 23230 & $1752(7.5)$ & 31840 & 2014 \\
1992 & 24147 & $1764(7.3)$ & 32489 & 1999 \\
1993 & 24270 & $1759(7.2)$ & 32489 & 2002 \\
1994 & 23893 & $1833(7.7)$ & 32059 & 2076 \\
1995 & 23483 & $1899(8.1)$ & 31801 & 2144 \\
1996 & 24111 & $1904(7.9)$ & 33081 & 2176 \\
1997 & 24681 & $1892(7.7)$ & 32849 & 2141 \\
1998 & 24894 & $1980(8.0)$ & 33113 & 2229 \\
1999 & 24289 & $1924(7.9)$ & 32352 & 2180 \\
\hline \multicolumn{5}{c}{} \\
\hline
\end{tabular}

Abbreviations: ICU, intensive care unit; ISS, Injury Severity Score; Ps, probability of survival; RTS, Revised Trauma Score; TRISS, Trauma and Injury Severity Score; UK MTOS, United Kingdom Major Trauma Outcome Study 
University of Crete's ethics committee approved the enrolment of patients in the trauma registry. We included patients in our trauma registry on the basis of the criteria of the United Kingdom Major Trauma Outcome Study (UK MTOS) - that is, patients who had sustained injuries resulting in immediate admission to hospital for three days or longer, admission to intensive care or high dependency unit, transfer between hospitals for further specialist care, or death in our hospital. On the basis of the same criteria we excluded patients over 65 years with isolated fracture of the femoral neck or pubic ramus and those with single uncomplicated limb injuries. ${ }^{15}$ Patients who died either at the scene or en route to the hospital were also excluded from the study. Moreover, as the department of paediatric surgery in our hospital constitutes a completely separate department and has its own trauma registry, children were excluded. Thus all motor-vehicle trauma patients over 14 years old who were admitted to our hospital between January 1997 and December 2000 and fulfilled the UK MTOS criteria were included in the present study.

The data collection for the trauma registry (including prehospital, emergency department, and inhospital information) was started immediately after a patient was admitted and continued on a daily basis. We collected data on:

- demographics

- mechanism of injury

- physiological condition on admission (systolic and diastolic arterial pressure, heart rate, breathing rate, and Glasgow Coma Scale)

- definitive anatomical injury diagnosis on discharge or death obtained from charts, radiology reports, or necropsies

- severity of total injury

- length of stay in the intensive care unit (ICU) and the hospital

- final outcome.

For determining the severity of injury we used the Injury Severity Score (ISS), Revised Trauma Score (RTS), and probability of survival (Ps) based on Trauma and Injury Severity Score (TRISS) methodology (software package: ICISScor; T Osler, New Mexico, 1995). ${ }^{16}$ The patient's age, type of injury (blunt or penetrating), ISS, and RTS were used to predict survival probability by TRISS analysis. ${ }^{16}$ We used the $\mathrm{M}$ statistic to evaluate the match of severity of injury between our patients and the Major Trauma Outcome Study (MTOS) database. ${ }^{17}$ We calculated the $\mathrm{W}$ statistic to evaluate the difference between the actual and predicted survival and the $\mathrm{Z}$ statistic, the statistical significance of this difference.

For the purpose of analysis, patients were divided into three groups based on the road-user category: car occupants, motorcyclists, and pedestrians. The car occupants' group included both the drivers and the passengers and, similarly, motorcycle drivers along with motorcycle co-drivers constituted the motorcyclists' group.

We performed the statistical analysis using one-way analysis of variance (ANOVA) and $\chi^{2}$ test where applicable. We applied the Kruskal-Wallis test for comparisons of medians. Values are presented as mean (SE) (standard error of the mean) and medians. Statistical significance was defined as $\mathrm{p}<0.05$.

\section{RESULTS}

\section{Study population and characteristics}

During the study period, 2580 adult trauma patients were admitted to the University Hospital of Herakleion. There were 1276 patients $(49.5 \%)$ with multiple trauma according to
Table 2 Demographic and injury data of the total study sample $(n=730)$

\begin{tabular}{|c|c|}
\hline Age in years* & $35.4(0.6) ; 29$ \\
\hline \multicolumn{2}{|l|}{ Sext } \\
\hline Men & $556(76.2)$ \\
\hline Women & $174(23.8)$ \\
\hline Heart rate (per minute)* & $87.6(0.6) ; 85$ \\
\hline Systolic arterial pressure $(\mathrm{mm} \mathrm{Hg})^{*}$ & $131.7(0.8) ; 130$ \\
\hline Diastolic arterial pressure $(\mathrm{mm} \mathrm{Hg})^{*}$ & $73.8(0.5) ; 73$ \\
\hline Breathing rate (per minute) ${ }^{*}$ & $18.3(0.1) ; 18$ \\
\hline Glasgow Coma Scale* & $14(0.8) ; 15$ \\
\hline Injury Severity Score* & $13.3(0.3) ; 10$ \\
\hline Revised Trauma Score* & $7.6(0.2) ; 7.84$ \\
\hline Probability of survival $^{*}$ & $0.97(0.03) ; 0.99$ \\
\hline Craniocerebral injuryt & $365(50)$ \\
\hline Thoracic injuryt & $222(30.4)$ \\
\hline Abdominal injuryt & $104(14.2)$ \\
\hline Spinal cord injury† & $70(9.6)$ \\
\hline Pelvic injury $†$ & $68(9.3)$ \\
\hline Upper and/or lower extremity injury† & $265(36.3)$ \\
\hline Intensive care unit (ICU) admissiont & $179(24.5)$ \\
\hline \multicolumn{2}{|l|}{ Length of stay (days)* } \\
\hline ICU & $7.9(0.6) ; 5$ \\
\hline Hospital & $11.7(0.5) ; 7$ \\
\hline Mortality & $35(4.8)$ \\
\hline
\end{tabular}

the UK MTOS criteria, and of these, 730 (57.2\%) were victims of vehicle accidents. These patients constituted our study population. ${ }^{15}$ Demographic and injury data of the total study population are given in table 2. Motorcyclists accounted for the majority of the study population. Of the 730 traffic accident victims, 444 (60.8\%) were motorcyclists, with 209 car occupants $(28.7 \%)$ and 77 pedestrians $(10.5 \%)$. Use of protective devices was rare; 35 of the injured car occupants (16.6\%) had used a seat belt and 27 of the motorcyclists $(6.1 \%)$ had used a helmet.

Epidemiological characteristics and initial vital signs of all three groups of road-users are shown in table 3. Comparison between car occupants, motorcyclists, and pedestrians revealed a variety of differences, many of which were statistically significant. The motorcyclists formed the youngest group of patients $(p=0.0001)$ with mean age under 30 years, although the car occupants were significantly younger than the pedestrians $(p=0.0001)$. Men comprised the vast majority of the injured motorcyclists. The proportion of men in the motorcyclist group was much higher than in the other two groups $(p=0.0001)$. This proportion was also higher in the car occupant group than among the pedestrians $(\mathrm{p}=0.0001)$.

\section{Injury profiles of the three road-user categories}

The injury characteristics of each group are presented in table 4. Craniocerebral injuries predominated among the motorcyclists and pedestrians. Car occupants were less susceptible to head trauma than both the other groups $(\mathrm{p}=0.0001)$ which had similar incidences. In contrast, abdominal $(p=0.009)$ and spinal cord trauma $(p=0.007)$ was more frequently observed among car occupants than in the other two road-user groups. Motorcyclists were more prone to abdominal trauma than pedestrians $(\mathrm{p}=0.009)$, and pelvic injuries were more frequent among the pedestrians $(p=0.0001)$ than the other two groups, of which the car occupants were more likely than the motocyclists to have sustained pelvic trauma $(p=0.0001)$. Even though car occupants did sustain more severe total injuries (as expressed by ISS) than both the other groups $(p=0.04)$, mortality in this group was similar to that in the motorcyclist group $(5.3 \%$ $v 3.4 \%, \mathrm{p}>0.05)$ and significantly lower than that of pedestrians $(5.3 \% \vee 11.7 \%, \mathrm{p}=0.007)$. 


\begin{tabular}{|c|c|c|c|c|}
\hline Variable & Car occupants & Motorcyclists & Pedestrians & $p$ value \\
\hline $\begin{array}{l}\text { Age in years } \dagger \\
\text { Sex }(\%)\end{array}$ & $42.7(1.2) ; 40$ & $28.1(0.6) ; 24$ & $57.7(2.4) ; 64$ & $\begin{array}{l}0.0001^{*} \\
0.0001^{*}\end{array}$ \\
\hline Men & 68.4 & 83.3 & 55.8 & \\
\hline Women & 31.6 & 16.7 & 44.2 & \\
\hline Heart rate (per minute) $†$ & $88.7(1.2) ; 85$ & $87.3(0.7) ; 85$ & $86.2(1.7) ; 84$ & 0.4 \\
\hline Systolic arterial pressure $(\mathrm{mm} \mathrm{Hg}) \dagger$ & $130.3(1.4) ; 130$ & $132.2(1.1) ; 130$ & $132.8(2.2) ; 135$ & 0.5 \\
\hline Diastolic arterial pressure $(\mathrm{mm} \mathrm{Hg}) \dagger$ & $73.4(1.1) ; 73$ & $74.1(0.7) ; 75$ & $73.5(1.5) ; 72$ & 0.8 \\
\hline Breathing rate (per minute) $\dagger$ & $18.5(0.3) ; 18$ & $18.2(0.2) ; 18$ & $17.8(0.4) ; 17$ & 0.4 \\
\hline Glasgow Coma Scale† & $14.1(0.1) ; 15$ & $14(0.1) ; 15$ & $14(0.2) ; 15$ & 0.8 \\
\hline
\end{tabular}

\section{Causes of death by road-user category}

Head trauma and haemorrhagic shock were the predominant causes of death among the injured car occupants. Of 11 deceased patients, 1 died due to acute respiratory distress syndrome $(9 \%), 5$ due to head injuries $(45.5 \%)$, and 5 because of haemorrhagic shock attributable to concomitant thoracic and abdominal trauma in all patients (45.5\%), in combination with pelvic trauma in 2 patients. Among the motorcyclists, head trauma was the primary cause of death resulting in 11 of the 15 observed deaths $(73.3 \%) ; 3$ patients $(20 \%)$ died due to haemorrhagic shock attributable to thoracic and abdominal injuries and $\mathrm{l}(6.7 \%)$ because of pulmonary embolism. Craniocerebral injuries were also the leading cause of death in pedestrians. Of the 9 deceased patients, $6(66.7 \%)$ died due to head trauma, $2(22.2 \%)$ because of haemorrhagic shock attributable to concomitant thoracic, abdominal, and pelvic injuries, and 1 (11.1\%) from septic shock. The lack of seat belt or helmet use was associated with death in all cases of car occupant or motorcyclist deaths as opposed to no deaths in protected patients.

A comparison of the causes of death in the three groups of patients revealed a significant difference. Death by blood loss was commoner among the fatalities in the car occupant group (45.5\% for car occupants $v 20 \%$ for motorcyclists and $22.2 \%$ for pedestrians, $\mathrm{p}=0.001$ for overall comparison). Death by head injury was commoner among the motorcyclists and pedestrians (73.3\% for motorcyclists and $66.7 \%$ for pedestrians $v 45.5 \%$ for car occupants, $\mathrm{p}=0.001$ for overall comparison).

\section{Probability of survival}

We calculated Ps for all patients. Of the non-survivors, one patient $(2.8 \%)$ had a Ps of less than $50 \%$. There were two unexpected survivors $(0.3 \%)$. The $\mathrm{W}$ statistic was calculated as -2.02 with a $z$ score of -3.84 . The $M$ statistic for our study sample was 0.92 , representing a good match between our patient population and the baseline patient groups based on the MTOS norms. ${ }^{17}$ We also calculated $\mathrm{W}$ and $\mathrm{Z}$ statistics for each group: -0.71 and -2.41 for car occupants, 0 and -0.87 for motorcyclists, and -0.95 and -5.46 for the pedestrians, respectively.

\section{DISCUSSION}

In past decades, the rates of motor vehicle related deaths have been consistently higher in the southern European countries than in the rest of Europe. Greece, Spain, and Portugal have two to four times higher mortality than countries with the lowest rates. ${ }^{78}$ Greece has one of the highest rates of death following vehicle accidents per million population in the European Union. ${ }^{6}$ Motor vehicle trauma is the leading cause of death of people under the age of 40, and it is the fifth commonest cause overall. ${ }^{3}$ Although several efforts have been made to reduce fatal vehicle accidents over the past years, mortality has remained essentially unchanged and must continue to be considered as a priority target for local prevention policies. Our results contribute to information regarding road users injured in motor vehicle crashes and admitted to a southern European level I trauma centre. Our particular objective was to identify and analyse injury profiles of these trauma patients depending on their roaduser status.

\section{Demographic features of patients in the different road-user categories}

Motorcycles yielded the greatest burden on traffic injuries as motorcyclists represented $60.8 \%$ of the study population. A striking contribution of motorcycle injuries has been reported in only three previous studies, all of which were conducted in the same setting (Barcelona, Spain), although the percentage

\begin{tabular}{|c|c|c|c|c|}
\hline Variable & Car occupants & Motorcyclists & Pedestrians & $\mathrm{p}$ value \\
\hline Injury Severity Score† & $14.3(0.7) ; 12$ & $12.7(0.4) ; 9$ & $13.3(1) ;(10)$ & $0.04^{*}$ \\
\hline Revised Trauma Score† & $7.6(0.2) ; 7.84$ & $7.6(0.2) ; 7.84$ & $7.6(0.2) ; 7.84$ & 0.8 \\
\hline Probability of survivalt & $0.97(0.03) ; 0.99$ & $0.96(0.02) ; 0.99$ & $0.97(0.02) ; 0.99$ & 0.9 \\
\hline Craniocerebral injury (\%) & 34.9 & 55.9 & 57.1 & $0.0001^{*}$ \\
\hline Thoracic injury $(\%)$ & 29.7 & 30.6 & 31.2 & 0.9 \\
\hline Abdominal injury (\%) & 20.1 & 12.6 & 7.8 & $0.009^{\star}$ \\
\hline Spinal cord injury (\%) & 14.8 & 7.9 & 5.2 & $0.007^{\star}$ \\
\hline Pelvic injury (\%) & 12.9 & 6.1 & 18.2 & $0.0001^{*}$ \\
\hline Extremity injury (\%) & 37.3 & 36 & 35.1 & 0.9 \\
\hline ICU admission (\%) & 27.8 & 22.5 & 27.3 & 0.2 \\
\hline ICU length of stay (days)t & $8.1(1.4) ; 4.5$ & $8.1(0.7) ; 6$ & $6.3(1.2) ; 3$ & 0.6 \\
\hline Hospital length of stay (days) $\dagger$ & $12.9(1.0) ; 8$ & $11.5(0.6) ; 7$ & $9.9(1.0) ; 7$ & \\
\hline Mortality & 5.3 & 3.4 & 11.7 & $0.007^{\star}$ \\
\hline
\end{tabular}


of injured motorcyclists was lower (ranging from 44\% to $47 \%) .{ }^{10-12}$ Unlike other European and non-European countries, motorcycle injuries predominate in the road traffic injury subset in southern European countries, highlighting the urgent need to implement local effective strategies to reduce the risk of injury associated with motorcycles. Education campaigns promoting safe riding habits and behaviour together with use of helmets must be implemented in order to achieve a reduction in the number of motorcycle casualties.

On comparing the three road-user groups, we found a difference in the age distribution with the pedestrians tending to come from a significantly older population than the car occupants and motorcyclists. Although pedestrian groups with a mean age lower than in our study have been described, ${ }^{18}{ }^{19}$ a greater proportion of older patients among pedestrians than among car occupants and motorcyclists has been observed in other studies. ${ }^{9-11}$ Furthermore, young patients constituted the vast majority of injured motorcyclists. Motorcyclists were significantly statistically younger than car occupants in our study. One explanation of the greater involvement of young patients, particularly men, in motorcycle crashes, compared with other population groups, is their greater exposure to the risks of motorcycling.

The rates of injuries among men substantially exceeded the rates among women in all road-user groups except for the pedestrian group, where women represented a major proportion of the injured cases. Other studies have also shown high rates of injury among women pedestrians. ${ }^{18}{ }^{19}$ In accordance with previous reports, ${ }^{10} 112021$ we also found that the predominance of men was significantly greater in the motorcyclist group than in car occupant group.

\section{Injury profiles of the three road-user categories}

There were significant differences in the spectrum of injuries based on the mechanism of injury in the three groups. Our results suggest an increased risk of head injury for pedestrians and motorcyclists. This finding is in agreement with other studies. ${ }^{920}$ There was no significant difference in the incidence of head trauma between the pedestrians and motorcyclists. Our results suggest that car occupants are at significantly higher risk of abdominal trauma when compared with motorcyclists and pedestrians and that, in addition, motorcyclists are more susceptible to abdominal injuries than pedestrians. These findings are similar to those of other reported series. ${ }^{913}$ The substantial differences in the frequency of abdominal trauma among car occupants and the rest of the study population may be attributed to the low percentage of use of seat belts observed in our patients. The incidence of spinal cord injury was much higher among car occupants as opposed to motorcyclists and pedestrians, who had similar incidences. A low frequency of spinal cord injuries in pedestrians and motorcyclists has been reported by others $^{19}{ }^{20}$; however, our results contrast with those of Hill et al, ${ }^{9}$ who reported that thoracolumbar fractures occurred more frequently in pedestrians than in car occupants. This difference might be explained by the fact that few injured car occupants (16.6\%) in our study had used a seat belt. Pelvic trauma is more common in pedestrians. ${ }^{918}$ In our study, pelvic injury was three times more frequent in pedestrians and two times more frequent in car occupants compared with motorcyclists.

Compared with other road users, car occupants had more severe injuries. There was no significant difference in the ISS between motorcyclists and pedestrians. This contrasts with studies which found no substantial difference between these three mechanisms of injury concerning total severity of injury, ${ }^{1013}$ as well as with Cirera et al, ${ }^{11}$ who reported a significantly higher risk of more severe injuries for pedestrians and motorcyclists. Perhaps the greater total severity of injuries among the car occupants in our study may be explained by the low use of safety belts among our patients. Despite campaigns aimed at encouraging use of safety belts, their use remains low in Greece and is reported to be one of the lowest in Europe. ${ }^{6}$

\section{Evaluation of mortality by road-user category}

Pedestrian trauma is associated with substantial morbidity and mortality and demands a high index of suspicion during initial evaluation. Pedestrians are a highly vulnerable population group among motor-vehicle trauma patients, with high mortality. ${ }^{10} 1922$ Our results also show that pedestrians in Greece are at significantly higher risk of inhospital mortality than the other two road-user groups. Although pedestrians represented $10.5 \%$ of the hospitalised victims, they accounted for $25.8 \%$ of all deaths. Such a high mortality among pedestrians compared with the other two road-user groups in our study, despite ISS similar to motorcyclists and lower than car occupants, could probably be explained by the higher percentage of craniocerebral injuries and the greater proportion of older patients in this group. Even though ISS has been reported to influence mortality of trauma patients, ${ }^{22-25}$ age $^{222425}$ and head trauma ${ }^{9326}$ have also been shown to affect mortality rates in these patients. Moreover, Oreskovich $e t a^{27}$ found that ISS was not predictive of survival in older injured patients, but they proved that the actual independent impact of head injury was one of the major predictors of fatal outcome in these patients. In addition, Luerssen et $a l^{28}$ indicated that "age itself, even within the pediatric age range, is a major independent factor affecting the mortality rate in headinjured patients". Comparison of cause of death in the three groups of patients revealed a significant difference, with death due to haemorrhagic shock being commoner among the fatalities in the car occupant group and death because of head injury more common among motorcyclists and pedestrians.

\section{Severity of injuries (TRISS methodology)}

TRISS methodology increases the objectivity of the assessment of outcomes and is widely applied in developed countries. We chose to use TRISS methodology in our study because of its ability to identify trends in the quality of trauma care. ${ }^{16}$ Our study population was well matched with the baseline patient groups. ${ }^{17}$ The actual survival of the total study population was lower than what was predicted based on TRISS norms. This finding was more noteworthy in the pedestrian group although it was also found in the car occupant group; no difference was observed in the motorcyclists. The difference in expected and observed mortality may be attributed to the quality of trauma care in hospital settings but it also reflects the quality of prehospital care including time to definitive care. In a country with limited infrastructure, a significant W score should be interpreted cautiously.

\section{Use of safety devices}

Multiple studies have confirmed the effectiveness of safety belts and helmets in decreasing mortality and injury severity after motor vehicle crashes. ${ }^{29}{ }^{30}{ }^{31}$ In our patients, the lack of seat belt or helmet use was associated with all deaths among the car occupants and motorcyclists as opposed to no deaths in protected patients. In Greece, compliance with safety restraint devices is low among car occupants and motorcyclists, resulting in high prehospital and inhospital mortality. Our study emphasises the need for more strict enforcement of laws related to the use of protective devices and also for public awareness campaigns and education 
programmes tartgeted at increasing safety belt and helmet utilisation in Greece.

\section{CONCLUSION}

The results of our study reveal a clear association between different road-user categories and age and sex incidence patterns as well as outcome and injury profiles observed. Recognition of these features would be useful in designing effective accident prevention strategies and in comprehensive prehospital, emergency department, and inhospital treatment of motor-vehicle trauma patients.

\section{Authors' affiliations}

H Markogiannakis, E Sanidas, D Tsiftsis, Department of Surgical Oncology, Herakleion Medical School, University of Crete, Greece H Markogiannakis, E Messaris, 1st Department of Propaedeutic Surgery, Hippocration Hospital, University of Athens, Greece

D Koutentakis, Department of Neurosurgery, Herakleion Medical

School, University of Crete, Greece

K Alpantaki, Department of Orthopaedics, Herakleion Medical School, University of Crete, Greece

A Kafetzakis, Department of Thoracic and Vascular Surgery, Herakleion Medical School, University of Crete, Greece

Competing interests: none declared

\section{REFERENCES}

1 MacKenzie EJ, Fowler CJ. Epidemiology. In: Mattox KL, Feliciano DV Moore EE, eds. Trauma, 4th edn. New York NY: McGraw-Hill, 2000:22-8.

2 Wang $Z$, Jiang J. An overview of research advances in road traffic trauma in China. Traffic Ini Prev 2003:4:9-16.

3 Social Welfare and Health Statistics 1991. Athens: National Statistical Service of Greece, 1994.

4 Social Welfare and Health Statistics 1993. Athens: National Statistical Service of Greece, 1996

5 Androulakis G. Multiple injured patients as an inhospital problem. In Androulakis G, Gousis P, eds. Proceedings of the Recovery Days Symposium on "Trauma". Athens: Zita editions, 1992:7-15.

6 Parliamentary Committee for the Study of Road Traffic Accidents Report: for road traffic accidents and road safety in Greece. Athens: Parliament of Greece, May 1996.

7 World Health Organization. World health statistics annual, 1995. Geneva: World Health Organization, 1996.

8 European Conference of Ministers of Transport (ECMT). Statistical report on road accidents in 1991. Paris: ECMT, 1993:50-1.

9 Hill DA, Delaney LM, Duflou J. A population-based study of outcome after injury to car occupants and to pedestrians. J Trauma 1996;40:351-5.

10 Plasència A, Borrell C, Ant JM. Emergency department and hospital admissions and deaths from traffic injuries in Barcelona, Spain. A one-year population-based study. Accid Anal Prev 1995;27:591-600.
11 Cirera $E$, Plasència A, Ferrando J, et al. Factors associated with severity and hospital admission of motor-vehicle injury cases in a southern European urban area. Eur J Epidemiol 2001;17:201-8.

12 Ferrando J, Plasència A, Ricart $\mathrm{I}$, et al. Motor-vehicle injury patterns in emergency-department patients in a south-European urban setting. Annu Proc Assoc Adv Automot Med 2000;44:445-58.

13 Rogers CD, Pagliarello G, McLellan BA, et al. Mechanism of injury influences the pattern of injuries sustained by patients involved in vehicular trauma. Can J Surg 1991;34:283-6.

14 Civil ID. Patterns of injury in motor vehicle trauma. N Z Med J 1986;99:905-6.

15 Yates D W, Woodford M, Hollis S. Preliminary analysis of the care of injured patients in UK hospitals: first report of the United Kingdom major trauma outcome study. BMJ 1992;305:737-40.

16 Van Natta TL, Morris JA Jr. Injury scoring and trauma outcomes. In: Mattox KL, Feliciano DV, Moore EE, eds. Trauma, 4th edn. New York NY: McGraw-Hill, 2000:69-80.

17 Champion HR, Copes WS, Sacco WJ, et al. The Major Trauma Outcome Study: establishing national norms for trauma care. J Trauma 1990;30:1356-65

18 Kong LB, Lekawa M, Navarro RA, et al. Pedestrian-motor vehicle trauma. An analysis of injury profiles by age. J Am Coll Surg 1996;182:17-23.

19 Peng RY, Bongard FS. Pedestrian versus motor vehicle accidents: an analysis of 5,000 patients. J Am Coll Surg 1999;189:343-8.

20 Begg DJ, Langley JD, Reeder Al. Motorcycle crashes in New Zealand resulting in death and hospitalisation. I: Introduction methods and overview. Accid Anal Prev 1994;26:157-64.

21 Langley JD, Begg DJ, Reeder Al. Motorcycle crashes resulting in death and hospitalisation. II: Traffic crashes. Accid Anal Prev 1994;26:165-71.

22 Hui T, Avital I, Soukiasian H, et al. Intensive care unit outcome of vehiclerelated injury in elderly trauma patients. Am Surg 2002;68:1111-14.

23 Gennarreli TA, Champion HR, Sacco WJ, et al. Mortality of patients with head injury and extracranial injury treated in trauma centers. J Trauma 1989;29:1193-202.

24 DeMaria EJ, Kenney PR, Merriam MA, et al. Survival after trauma in geriatric patients. Ann Surg 1987;206:738-43.

25 Morris JA Jr, MacKenzie EJ, Damiano AM, et al. Mortality in trauma patients: the interaction between host factors and severity. J Trauma 1990:30:1476-82.

26 Swierzewski MJ, Feliciano DV, Lillis RP, et al. Deaths from motor vehicle crashes: patterns of injury in restrained and unrestrained victims. J Trauma 1994;37:404-7.

27 Oreskovich MR, Howard JD, Copass MK, et al. Geriatric trauma: injury patterns and outcome. J Trauma 1984;24:565-9; discussion 569-72.

28 Luerssen TG, Klauber MR, Marshall LF. Outcome from head injury related to patient's age. A longitudinal prospective study of adult and pediatric head injury. J Neurosurg 1988;68:409-16.

29 McGwin G, Metzger J, Alonso JE, et al. The association between occupant restraint systems and risk of injury in frontal motor vehicle collisions. J Trauma 2003;54:1182-7

30 Gngora E, Acosta JA, Wang DSY, et al. Analysis of motor vehicle ejection victims admitted to a level I trauma center. J Trauma 2001;51:854-9.

31 Ferrando J, Plasència A, Ors $M$, et al. Impact of a helmet law on two-wheel motor vehicle crash mortality in a southern European urban area. Inj Prev 2000;6:184-8. 